\title{
Gambaran Keterampilan Sadari Sebelum dan Sesudah Dilakukan Penyuluhan Melalui Media Audio Visual pada Remaja Putri
}

\section{Description of awareness skills before and after counseling through audio visual media for teenager}

\author{
Nuning Epita*, Anis Nikmatul Nikmah, Putri Wahyu Wigati \\ * Program Studi D3 Kebidanan, Fakultas IImu Kesehatan,Universitas Kadiri \\ Jl. Selomangleng 1 Kediri Kode Pos 64111-64119 \\ e-mail: nuningepita@gmail.com
}

\begin{abstract}
ABSTRAK
SADARI (pemeriksaan payudara sendiri) adalah pemeriksaan awal yang dilakukan sendiri untuk deteksi dini terhadap adanya gejala kanker payudara. Dengan mengetahui adanya kanker payudara sejak awal, kemungkinan sembuh semakin besar. Berdasarkan survey pendahuluan di prodi farmasi semester 2 terdapat 16 remaja putri yang masih rendahnya keterampilan tentang keterampilan SADARI. Tujuan penelitian ini adalah untuk mengetahui apakah ada perbedaan keterampilan SADARI sebelum dan sesudah dilakukan penyuluhan melalui media audio visual pada remaja putri di prodi farmasi semester 2 Universitas Kadiri tahun 2020.

Penelitian ini merupakan penelitian deskriptif komparatif. Populasi dalam penelitian ini adalah seluruh remaja semester $2 b$ di prodi farmasi universitas kadiri. Sampel dalam penelitian ini adalah sebagian remaja putri di prodi farmasi semester 2. Tehnik sampling yang digunakan adalah simple random sampling dengan instrument pengumpulan data menggunakan lembar cheklist. Tabulasi digambarkan dalam bentuk distribusi frekuensi dengan menggunakan tehnik analisa presentase danhasilnya menggunakan tabulasi silang.

Hasil penelitian dari 30 sampel sebagian besar remaja sebelum dilakukan penyuluhan sebanyak $20(66,7 \%)$ termasuk dalam kategori awal, sesudah dilakukan penyuluhan hampir seluruh remaja dalam kategori mahir yaitu sebanyak 25 (83,3\%).

Kesimpulan penelitian menunjukan ada perbedaan keterampilan SADARI sebelum dan sesudah dilakukan penyuluhan melalui media audio visual pada remaja putri di Prodi Farmasi Universitas Kadiri Tahun 2020. Saran peneliti diharapkan dari penelitian ini dapat menambah pengetahuan dan wawasan sebagai informasi untuk melakukan upaya peningkatan keterampilan tentang SADARI.
\end{abstract}

Kata kunci : Kesehatan, SADARI, Keterampilan 


\section{ABSTRACT}

BSE (breast self-examination) is an initial self-examination for early detection of breast cancer symptoms. By knowing the presence of breast cancer early, the chances of a cure are even greater. Based on the preliminary survey in the second semester of pharmacy study program, there are 16 young women who still have low skills regarding BSE skills. The purpose of this study was to determine whether there were differences in BSE skills before and after counseling through audio-visual media for young women in the second semester of pharmacy study program at Kadiri University in 2020.

This research is a comparative descriptive study. The population in this study were all $2 b$ semester adolescents in the Kadiri University Pharmacy study program. The sample in this study were some young women in the second semester of pharmacy study program. The sampling technique used was simple random sampling with data collection instruments using a checklist sheet. Tabulation is described in terms of frequency distribution using percentage analysis techniques and the results using cross tabulation.

The results of the research, most of the 30 samples of adolescents before the extension were carried out as many as 20 (66.7\%) were included in the initial category, after counseling almost all adolescents were in the advanced category, namely 25 (83.3\%).

The conclusion of the study shows that there are differences in BSE skills before and after counseling through audio-visual media for young women in the Pharmacy Study Program at Kadiri University in 2020. Researchers' suggestions are expected from this study to increase knowledge and insight as information to make efforts to improve BSE skills.

Keywords: Health, BSE, skills

\section{PENDAHULUAN}

Kanker payudara merupakan ancaman yang menakutkan bagi kaum perempuan. Kanker payudara merupakan jenis ganas yang sangat ditakuti karena kanker ini menepati urutan kedua setelah kanker leher rahim. Oleh sebab itu, permasalahan kanker payudara ini membutuhkan perhatian khusus, baik dari perempuan sendiri (yang rentan terserang kanker tersebut) maupun seluruh masyarakat(Sitiatava, 2015). Angka kejadian kanker payudara lebih tinggi pada negara-negara maju dibandingkan negara berkembang, hal ini dikarenakan perubahan gaya hidup dan kondisi sosial ekonomi di negara maju berkaitan dengan peningkatan resiko terjadinya kanker payudara (Savitri, 2015).

Berdasarkan Data Global Cancer Observatory 2018 dari World Health Organization (WHO) menunjukan kasus yang paling banyak terjadi di indonesia adalah kanker payudara, yaitu 58.256 kasus atau 16,7\% dari total 348.809 kasus kanker. Kementrian Kesehatan (Kemenkes) menyatakan, angka kanker payudara 
di indonesia mencapai 42,1 orang per 100 ribu penduduk. Rata-rata kematian akibat kanker payudara ini mencapai 17 orang per 100 ribu penduduk (WHO,2019). Menurut Pudastin tahun 2015, estimasi jumlah penderita kanker serviks dan kanker payudara di jawa timur sebesar 21.313 kasus dan 9.688 orang (Kemenkes RI, 2015). Pada tahun 2018 di kota kediri data untuk deteksi dini kanker leher rahim dengan metode IVA dan kanker payudara dengan pemeriksaan klinis (CBE) pada perempuan usia 30-50 tahun adalah sebanyak 5.946 orang $(2 \%)$ dengan iva positif 244 orang $(4,10)$ dan ada tumor dan benjolan sejumlah 72 orang (1,21\%) (Dinkes Kota Kediri, 2018).

Berdasarkan hasil survey yang telah dilakukan pada tanggal 9 maret 2020 di prodi farmasi semester $2 \mathrm{~b}$ universitas kadiri yang dilakukan pada 17 remaja didapatkan hasil, diketahui bahwa dari 17 remaja tersebut hanya 1 remaja $(5,8 \%)$ yang sudah pernah mendapatkan informasi tentang SADARI tetapi tidak diterapkan dan 16 remaja (94,2\%) lainya belum pernah mendapatkan informasi tentang SADARI serta mereka tidak tahu apa itu SADARI. Dengan ini didapatkan rendahnya pengetahuan keterampilan tentang SADARI di prodi farmasi $2 b$ tahun 2020.

Faktor-faktor resiko yang bisa dilihat pada wanita seperti memiliki riwayat tumor, haid terlalu muda, pola makan yang tidak sehat dengan konsumsi lemak berlebih, pecandu alkohol, stres dan kegemukan (Sitiatava, 2015). Beberapa kasus kanker payudara yang dapat berujung kematian disebabkan oleh keterlambatan dalam penanganan. Kebanyakan pasien tidak menyadari tandatanda kanker payudara sehingga terlambat dalam memeriksa diri. Hal ini menyebabkan penanganannya juga terlambat bahkan saat pasien sudah memasuki kanker payudara stadium lanjut dimana resiko kematian semakin besar. Oleh karna itu, setiap orang harus mengetahui gejala-gejala dari kanker payudara sehingga penanganan dapat dilakukan lebih dini (Siregar, 2015).

Pemeriksaan awal atau deteksi dini terhadap adanya gejala kanker payudara sangat penting dilakukan dengan menggunakan pemeriksaan yang mudah dan dapat dilakukan sendiri, yaitu pemeriksaan payudara sendiri (SADARI). SADARI ini bertujuan agar dapat mengantisipasi secara cepat jika ditemukan benjolan pada payudara karena hampir $85 \%$ kelainan pada payudara ditemukan pertama kali oleh penderita (Sitiatava, 2015).SADARI juga sebaiknya mulai dilakukan saat seorang wanita telah mengalami menstruasi, karena tingkat sensitivitasnya (kemampuan untuk deteksi kanker payudara) dan dilakukan pada hari ke 5-7 setelah menstruasi (Savitri, 2015).

Pentingnya melakukan SADARI sudah menjadi program pemerintah dalam upaya penanggulangan kejadian kanker payudara. Hal tersebut tertuang dalam Peraturan Menteri Kesehatan Republik Indonesia nomor 34 tahun 2015 tentang "Penanggulangan Kanker Payudara Dan Kanker Rahim" (Kemenkes RI, 2015). Selama 5 tahun terakhir program pengendalian kanker payudara telah dilakukan secara terorganisir. Direktorat Jendral Pengendalian Penyakit dan PenyehatanLingkungan (P2PL) Kemenkes RI menyatakan bahwa, terdapat 5 kegiatan utama yang telah disusun dan dilaksanakan di Indonesia, yaitu program 
promotif dan pencegahan, program deteksi dini dan tindak lanjut dini, surveilans dan registrasi kanker, diagnosa dan pengobatan, pelayanan paliatif.

Penyuluhan kesehatan merupakan suatu promosi kesehatan yang berupa memberikan informasi atau pesan kesehatan untuk meningkatkan pengetahuan, kesadaran, kepedulian, dan kemauan menerapkan pola hidup sehat (Emilia dkk, 2019). Pengetahuan dapat bertambah dengan adanya informasi dari berbagai macam media seperti media cetak ataupun media elektronik.Penyuluhan dengan media audio visual merupakan media yang mengandung unsur suara dan juga mengandung unsur gambar yang dapat dilihat, seperti video, dengan berbagai ukuran film, slide suara dan lainnya. Kemampuan media audio visual dianggap lebih baik dan lebih menarik, karena mengandung dua unsur yaitu dapat dilihat dan didengar.Dengan media ini diharapkan dapat meningkatkan keterampilan dalam melakukan SADARI (Ummyssalam, 2017).

Hal ini sejalan dengan penelitian yang dilakukan oleh(Arida,dkk, 2019) dengan Judul Perbedaan Efektifitas Pendidikan Kesehatan SADARI Dengan Menggunakan Media Leaflet Dan Media Audio Visual Pada Remaja Purti Di SMK NU UNGARAN berdasaran hasil penelitiannya didapatkan bahwa penggunaan media audio visual memiliki pengaruh yang lebih tinggi terhadap pengetahuan remaja putri dibandingkan penggunaan media leaflet.

Hasil penelitian yang dilakukan oleh (Mei Faitmah dan Mujahidatul, 2017) dengan judul Perbedaan Media Promosi Kesehatan Booklet Dan Video Terhadap Keterampilan Deteksi Dini Kanker Payudara Pada Wanita Usia Subur Di Kedunglumbu dengan hasil penelitiannya bahwa perbedaan nilai rata-rata kedua kelompok menunjukkan bahwa media video memberikan hasil yang lebih baik dari pada media booklet.

Dibalik banyaknya manfaat yang dirasakan dan caranya yang mudah untuk melakukan SADARI, serta program dari pemerintah yang sudah dicanangkan masih banyak kejadian kanker payudara.Hanya beberapa perempuan yang mau melakukan SADARI dan masih banyak perempuan yang enggan melakukannya. Hal inilah yang menjadi penyebab masih tingginya angka kematian akibat kanker payudara dan keterlambatan diagnosa dan penanganan oleh tenaga medis.

Berdasarkan uraian tersebut maka penulis tertarik melakukan penelitian dengan judul "Gambaran Keterampilan SADARI Sebelum dan Sesudah Dilakukan Penyuluhan Melalui Media Audio Visual Pada Remaja Putri Di Prodi Farmasi Universitas Kadiri".

\section{METODE PENELITIAN}

Penelitian ini merupakan penelitian deskriptif komparatif. Populasi dalam penelitian ini adalah seluruh remaja semester $2 b$ di prodi farmasi universitas kadiri. Sampel dalam penelitian ini adalah sebagian remaja putri di prodi farmasi semester 2. Tehnik sampling yang digunakan adalah simple random sampling dengan instrument pengumpulan data menggunakan lembar cheklist. Tabulasi digambarkan dalam bentuk distribusi frekuensi dengan menggunakan tehnik 
analisa presentase dan hasilnya menggunakan tabulasi silang.

\section{HASIL DAN PEMBAHASAN}

\section{Hasil}

Tabel 1 Karakteristik Frekuensi Responden Berdasarkan Kelompok Umur Di Prodi Farmasi Semester 2 Universitas Kadiri Tahun 2020

\begin{tabular}{ccc}
\hline No. & Umur & Presentase \\
\hline 1. & $11-14$ tahun & - \\
2. & $15-17$ tahun & - \\
3. & $18-21$ tahun & $100 \%$ \\
& Jumlah & $100 \%$
\end{tabular}

Sumber : Data primer penelitian 2020

Berdasarkan data pada tabel 1 dapat diinterpretasikan bahwa seluruh responden berumur 18- 21 tahun sejumlah 30 (100\%) responden.

Tabel 2 Karakteristik Frekuensi Responden Berdasarkan Informasi Yang Pernah Didapat Di Prodi Farmasi Semster 2 Universitas Kadiri Tahun 2020

\begin{tabular}{cccc}
\hline No. & Kriteria & Frekuensi & Presentase \\
\hline 1. & Pernah & 9 & $30 \%$ \\
2. & Tidak pernah & 21 & $70 \%$ \\
& Jumlah & 30 & $100 \%$
\end{tabular}

Sumber : Data primer penelitian 2020

Berdasarkan data pada tabel 2 dapat diinterpretasikan bahwa sebagian besar responden tidak pernah mendapatkan informasi tentang SADARI yaitu sebanyak $21(70 \%)$ responden.

Tabel 3 Karakteristik Frekuensi Responden Berdasarkan Sumber Informasi Yang Pernah Didapat Di Prodi Farmasi Semster 2 Universitas Kadiri Tahun 2020

\begin{tabular}{cccc}
\hline No. & Kriteria & Frekuensi & Presentase \\
\hline 1. & Media Sosial & 5 & $16,7 \%$ \\
2. & Tenaga Kesehatan & 4 & $13,3 \%$ \\
3. & Tidak Ada & 21 & $70 \%$ \\
& Jumlah & 30 & $100 \%$
\end{tabular}

Sumber : Data primer penelitian 2020

Berdasarkan data pada tabel 3 dapat diinterpretasikan bahwa sebagian besar responden belum mendapatkan informasi tentang SADARI yaitu sebanyak 21 (70\%) responden. 
Tabel 4 Distribusi frekuensi gambaran keterampilan SADARI sebelum dilakukan penyuluhan melalui media audio visual pada remaja putri di Prodi Farmasi Semester 2 Universitas Kadiri Tahun 2020

\begin{tabular}{cccc}
\hline No. & Kriteria & Frekuensi & Presentase \\
\hline 1. & Baik & 1 & $3,3 \%$ \\
2. & Cukup & 5 & $16,7 \%$ \\
3. & Kurang & 24 & $80,0 \%$
\end{tabular}

Sumber : Data primer penelitian 2020

Berdasarkan tabel 4 dapat dilihat, keterampilan SADARI sebelum dilakukan penyuluhan dengan media audio visual pada remaja putri Prodi Farmasi Universitas Kadiri Tahun 2020 hampir seluruh remaja dengan presentase $(80,0 \%)$ termasuk dalam kategori kurang.

Tabel 5 Distribusi frekuensi gambaran keterampilan SADARI sesudah dilakukan penyuluhan melalui media audio visual pada remaja putri di Prodi Farmasi Semester 2 Universitas Kadiri Tahun 2020

\begin{tabular}{cccc}
\hline No. & Kriteria & Frekuensi & Presentase \\
\hline 1. & Baik & 25 & $83,3 \%$ \\
2. & Cukup & 5 & $16,7 \%$ \\
3. & Kurang & - & $100 \%$
\end{tabular}

Sumber : Data primer penelitian 2020

Berdasarkan tabel 5 dapat dilihat, keterampilan SADARI sesudah dilakukan penyuluhan dengan media audio visual pada remaja putri Prodi Farmasi Universitas Kadiri Tahun 2020 hampir seluruh remaja dengan presentase $(83,3 \%)$ termasuk dalam kategori baik.

Tabel 6 Tabulasi perbedaan keterampilan sebelum dan sesudah dilakukan penyuluhan melalui media audio visual pada putri di prodi farmasi semester 2 Universitas Kadiri tahun 2020.

\begin{tabular}{ccccc}
\hline \multirow{2}{*}{$\begin{array}{c}\text { Kriteria } \\
\text { Keterampilan }\end{array}$} & \multicolumn{4}{c}{ Keterampilan } \\
\cline { 2 - 5 } & \multicolumn{2}{c}{ Sebelum } & \multicolumn{2}{c}{ Sesudah } \\
\cline { 2 - 5 } & $\mathbf{f}$ & $\mathbf{\%}$ & $\mathbf{f}$ & $\mathbf{\%}$ \\
\hline Baik & 1 & 3,3 & 25 & 83,3 \\
Cukup & 5 & 16,7 & 5 & 16,7 \\
Kurang & 24 & 80,0 & - & - \\
Total & 30 & 100 & 30 & 100
\end{tabular}

Sumber : Data primer penelitian 2020

Berdasarkan tabel 6 dapat dilihat bahwa, sebelum dilakukan penyuluhan melalui audio visual hampir seluruh dari responden dengan keterampilan kurang yaitu sebanyak $24(80,0 \%)$ responden, dan setelah dilakukan penyuluhan melalui audio visual hampir seluruhnya dengan keterampilan baik yaitu sebanyak 25 
$(83,3 \%)$ responden.

\section{PEMBAHASAN}

\section{Gambaran keterampilan SADARI sebelum dilakukan penyuluhan melalui media audio visual pada remaja putri di Prodi Farmasi Universitas Kadiri Tahun 2020}

Hasil penelitian yang dilakukan di Prodi Farmasi Semester 2 Universitas Kadiri Tahun 2020 sebelum dilakukan penyuluhan SADARI melalui media audio visual pada tabel 4 didapatkan dari total 30 responden hampir seluruhnya yaitu 24 responden $(80,0 \%)$ termasuk dalam kategori kurang dalam melakukan SADARI dan 5 responden $(16,7 \%)$ termasuk Dalam kategori cukup dalam melakukan SADARI. Dari penelitian didapatkan kurangnya keterampilan remaja dalam melakukan SADARI sehingga remaja tersebut kurang terampil dalam melakukan SADARI. Keterampilan adalah kemampuan seseorang dalam menerapkan pengetahuan. Keterampilan SADARI merupakan kemampuan seseorang dalam menerapkan cara melakukan SADARI yang benar (Rusmala, 2015).

SADARI adalah pemeriksaan awal atau deteksi dini terhadap adanya gejala kanker payudara.Dengan mengetahui adanya kanker payudara sejak awal, kemungkinan semuh semakin besar.Sebab, kunci penanganan kanker payudara adalah pada tahap awal (Sitiatava, 2015). Pemeriksaan adalah proses, cara, penyelidikan secara teknis terhadap kelenjar susu atau payudara (Nisman, 2011). Menurut peneliti kurangnya keterampilan SADARI pada remaja putri di prodi farmasi semester 2 tersebut dikarenakan kebanyakan dari mereka belum pernah mendapat informasi tentang SADARI dan sebagian besar remaja tersebut yang seharusnya bisa memanfaatkan gadget sebagai sumber informasi tidak dimanfaatkan secara optimal untuk mencaritahu tentang pemeriksaan SADARI.

\section{Gambaran keterampilan SADARI sesudah dilakukan penyuluhan melalui media audio visual pada remaja putri di Prodi Farmasi Universitas Kadiri Tahun 2020}

Hasil penelitian yang dilakukan di Prodi Farmasi Semester 2 Universitas Kadiri Tahun 2020 sesudah dilakukan penyuluhan SADARI melalui media audio visual pada tabel 5 didapatkan dari total 30 responden terdapat 25 responden $(83,3 \%)$ mahir dalam melakukan SADARI dan hanya 5 responden $(16,7 \%)$ terampil dalam melakukan SADARI. Dari hasil penelitian ini hampir seluruh responden mahir dalam melakukan SADARI. Menurut penelitian yang dilakukan oleh(Arida,dkk, 2019) dengan Judul Perbedaan Efektifitas Pendidikan Kesehatan SADARI Dengan Menggunakan Media Leaflet Dan Media Audio Visual Pada Remaja Putri di SMK NU UNGARAN.

Didapatkan hasil dari 34 responden kelompok Audio Visual, sebelum diberikan pendidikan kesehatan menggunakan audio visual, rata-rata skor pengetahuan remaja putri tentang Pemeriksaan Payudara Sendiri (SADARI) sebesar 27,12 dengan standar deviasi 3,88. Skor paling rendah sebesar 18 dan 
paling tinggi sebesar 33. Kemudian sesudah diberikan pendidikan kesehatan menggunakan audio visual, rata-rata skor pengetahuan remaja putri tentang Pemeriksaan Payudara Sendiri (SADARI) berubah menjadi 33,59 dengan standar deviasi 2,68. Skor paling rendah menjadi 26 dan paling tinggi menjadi 38. Hal ini juga sejalan menurut penelitian yang dilakukan oleh (Mei Faitmah dan Mujahidatul, 2017) dengan judul Perbedaan Media Promosi Kesehatan Booklet Dan Video Terhadap Keterampilan Deteksi Dini Kanker Payudara Pada Wanita Usia Subur Di Kedunglumbu, dengan hasil penelitian menunjukkan nilai keterampilan SADARI kelompok booklet setelah diberikan media promosi kesehatan mengalami peningkatan, namun tidak dapat mencapai keterampilan yang maksimal dengan skor tertinggi hanya 7. Selisih nilai mean pretes dan postes sebesar 4,00 dengan nilai rentang skor keterampilan sebesar 4. Nilai rerata keterampilan SADARI kelompok video setelah diberikan media promosi kesehatan mengalami peningkatan yang signifikan dan dapat mencapai keterampilan yang maksimal dengan skor maksimal 12 .

Keterampilan pemeriksaan payudara sendiri (SADARI) merupakan kemampuan seseorang untuk mengendalikan pikiran dan tindakan sendiri secara bebas dalam melakukan atau mempraktekkan cara pemeriksaan payudara sendiri (SADARI).SADARI ini bertujuan agar dapat mengantisipasi secara cepat jika ditemukan benjolan pada payudara karena kelainan pada payudara ditemukan pertama kali oleh penderita (Sitiatava, 2015).

Dengan demikian, penemuan kanker payudara sejak dini sangatlah penting untuk sebuah kesembuhan. Tujuan utama deteksi dini kanker payudara adalah untuk menemukan kanker dalam stadium dini (level 1), sehingga pengobatannya menjadi lebih baik. Menurut Endang Purwoastuti, 75- 80\% keganasan kanker payudara ditemukan pada saat dilakukan pemeriksaan sendiri (SADARI) (Sitiatava, 2015). Pemeriksaan payudara sendiri sangat dianjurkan kepada masyarakat karena hampir $86 \%$ benjolan di payudara ditemukan oleh penderita sendiri.

\section{Analisis perbedaan keterampilan sebelum dan sesudah dilakukan penyuluhan melalui media audio visual pada remaja putri di Prodi Farmasi Universitas Kadiri Tahun 2020}

Menurut pendapat peneliti, bahwa adanya perbedaan keterampilan SADARI pada remaja putri di Prodi Farmasi Universitas Kadiri Tahun 2020. Distribusi frekuensi responden berdasarkan keterampilan sebelum dan sesudah penyuluhan pada tabel4 menunjukan bahwa adanya perubahan keterampilan SADARI pada remaja putri hanya 1 responden yang dikatakan baik dan 29 responden lainya dalam kategori cukup dan kurang dikarenakan remaja tersebut belum pernah mendapatkan informasi tentang SADARI, sehingga keterampilan dalam melakukan SADARI pada remaja tersebut dalam kategori kurang. Hal ini menunjukan adanya perlakuan kepada responden dengan memberikan penyuluhan keterampilan SADARI melalui audiovisual pada remaja.

Data hasil penelitian ini menunjukan bahwa penyuluhan kesehatan 
mempunyai pengaruh dan manfaat yang baik dalam meningkatkan keterampilan seseorang tentang cara melakukan SADARI yang benar. Hasil penelitian ini sesuai dengan pendapat Notoatmodjo (2015) yang menyatakan bahwa pendidikan kesehatan merupakan upaya atau kegiatan untuk menciptakan perilaku masyarakat yang baik untuk kesehatan. Oleh karena itu dengan diberikan penyuluhan maka remaja mengerti, mengetahui dan mempraktekkan sendiri sehingga dapat menambah keterampilan remaja tentang cara melakukan SADARI dengan benar. Dari penelitian didapatkan hasil bahwa terdapat perbedaan keterampilan sebelum dan sesudah penyuluhan SADARI pada remaja putri di prodi farmasi semester 2 Universitas Kadiri Tahun 2020.

Ada perlakuan pada remaja dengan memberikan penyuluhan melalui audiovisual yang menyebabkan terjadinya perubahan keterampilan antara sebelum dan sesudah penyuluhan, sesuai fakta dilapangan keterampilan sebelum penyuluhan 24 responden $(80,0 \%)$ dalam kategori kurang dan 5 responden $(16,7 \%)$ dalam kategori cukup, setelah diberikan penyuluhan 25 responden $(83,3 \%)$ menjadi mahir. Dengan memberikan penyuluhan pada remaja menyebabkan terjadinya perbedaan tingkat keterampilan.

\section{KESIMPULAN}

Keterampilan SADARI sebelum penyuluhan hampir seluruh remaja dalam ketegori kurang pada remaja putri di Prodi Farmasi Universitas Kadiri. Namun, sesudah dilakukan penyuluhan melalui media audio visual pada remaja putri di Prodi Farmasi Universitas Kadiri hampir seluruh remaja putri keterampilan SADARI-nya menjadi baik. Sehingga disimpulkan ada perbedaan keterampilan SADARI sebelum dan sesudah dilakukan penyuluhan melalui media audio visual pada remaja putri di Prodi Farmasi Universitas Kadiri.

\section{SARAN}

Diharapkan hasil penelitian ini dapat dijadikan sebagai tambahan referensi dan informasi untuk pengembangan koleksi pustaka sehingga menambah wawasan bagi mahasiswa selain itu dengan penelitian ini diharapkan dapat mengungkapkan lebih banyak permasalahan dan memberikan pemecahan yang berguna bagi banyak pihak, dapat digunakan sebagai acuan dalam melakukan penelitian selanjutnya, untuk membantu variabel lain yang belum di bahas dalam penelitian ini, dengan penelitian ini diharapkan responden dapat menambah pengetahuan dan wawasan sebagai informasi remaja untuk melakukan upaya peningkatan keterampilan tentang SADARI. Tenaga kesehatan hendaknya lebih banyak memberikan wawasan tentang keterampilan melakukan SADARI agar bertambahnya pengetahuan sehingga responden mampu mengaplikasikan atau mempraktekkan SADARI pada remaja secara rutin. Dan sebaiknya meningkatkan keterampilan kepada remaja tentang melakukan SADARI sehingga dapat menunjang keberhasilan peningkatan kesehatan. 


\section{UCAPAN TERIMA KASIH}

Segala puji hanyalah bagi ALLAH S.W.T. Rabb semesta alam. Ucapan terima kasih kepada Universitas Kadiri yang bersedia dijadikan tempat penelitian, dosen pembimbing ibu Anis Nikmatul Nikmah dan ibu Putri Wahyu Wigati yang dengan sabar membimbing dan terima kasih kepada kedua orang tua saya yang selalu mendukung dan selalu mendoakan saya.

\section{DAFTAR PUSTAKA}

Fatimah, M., \& Musfiroh. M. (2017). Perbedaan Media Promosi Kesehatan Booklet danVideo Terhadap Keterampilan Deteksi Dini Kanker Payudara pada Wanita Usia Subur.

Nisman, \& Artanty, W. (2011). Lima Menit Kenali Payudara. Yogyakarta: C.V. Andi.

Notoatmodjo, S. (2012). Metodologi Penelitian Kesehatan. Jakarta: Rineka Cipta.

Pratiwi, A. W., Afriyani, L. D., \& Zulkarnain (2019). Perbedaan Efektifitas Pendidikan Kesehatan Pemeriksaan

Putra, F. E., \& Agustina, R. (2019). Buku Ajar Komunikasi Kesehatan. Jakarta: Prenada Media.

Putra, S. R. (2015). Buku Lengkap Kanker Payudara. Yogyakarta: Laksana.

Wiraswati, H. L., Ekawardhani, S., Windria, S., \& Faridah, L. (2019). Meningkatkan Keterampilan Kader Kesehatan dalam Melakukan Pemeriksaan Payudara Sendiri (SADARI). Jurnal Endurance : Kajian IImiah Problema Kesehatan, 1-9.

Yulinda, A., \& Fitriyah, N. (2018). Efektifitas Penyuluhan Metode Ceramah dan Audiovisual Dalam Meningkatkan Pengetahuan dan Sikap Tentang SADARI Di SMKN 5 Surabaya. Jurnal Promkes, 1-13. 